\title{
The Prompt Design of CNC Grinder Based on Flexible Product Platform
}

\author{
Dequan Gan, Ping Jiang, Huangao Zhang, and Zishun Chen \\ School of Mechanical Engineering, Hebei University of Technology, \\ 300130, Tianjin, China \\ \{Dequan.Gan, Ping.Jiang, Huangao.Zhang, Zishun.Chen, \\ Jiangping\} @hebut.edu.cn
}

\begin{abstract}
In mass customization the product platform is the power method to improve the reused ability of existing design resource. But to the high degree modularity product, the module limits the commonality of product platform. The flexible product platform solves the conflict of modularity's variety and commonality. The platform parameters denote the common properties of product platform and different values of those parameters realize the flexible of product platform. Then the parameter-independent modules can be combined into a physical product platform and extend to satisfy much more market segments. The flexible product platform of $\mathrm{CNC}$ grinder improves the reutilization and guides the designer promptly to develop the individual $\mathrm{CNC}$ grinder for personal customer needs.
\end{abstract}

Keywords: Flexible product platform, Platform parameter, CNC grinder, Prompt Design.

\section{Introduction}

Mass customization is defined as a delivery process through which mass-market goods and services are individualized to satisfy a very specific customer need, at an affordable price. Based on the public's growing desire for product personalization, it serves as the ultimate combination of "custom-made" and "mass production" [1]. Mass customization is optimized to build a wide range of products at the lowest possible cost and deliver them quickly. It requires that companies design products from the point of commonality, compatibility, standardization, or modularization among different products or product lines [2]. So product family and product platform are the bases of mass customization. Product family is defined as a group of related products that share common features, components, and subsystems; and satisfy a variety of market niches [3]. The product platform is defined as a set of subsystems and interfaces that form a common structure from which a stream of related products can be developed and produced efficiently within a given product family [4].

Hence the product platform has two characters: modularity and standardization [5]. Modularity embodies the flexible property and it means that diverse modules can build up into a serial of products to cater for different market segments. Standardization represents the stability and the product platform demands highly commonality of 
modules among the product family to improve the reused ability of product structures. From the view of mass customization, modularity realizes the customization and standardization implements mass production. In either case, platform components, systems or processes end up constraining the variants' design: because of the requirement that a platform component or process is identical in all variants, customized components are necessarily designed to be compatible with the platform; indeed, the range of possible (or desirable) customization in the entire product family is dictated by the platform [6]. Then the degree of modularity is higher may result lower of the standardization for too many modules can implement so much variety and the relations of modules become complex and influence the commonality of modules.

So this paper introduce flexible element to build up a flexible product platform. The flexible elements are related to main product characteristic which is generalized according to the customer needs. The main product characteristic is the core requirements of customer which indicate basic attribute of product platform. The flexible elements remain independence and can be combined together to improve the flexibility of product and reused ability of modules.

\section{Flexible Product Platform Design}

The goal of flexible product platform is to improve the adaptability of modules for different market niches. One of the main drivers for such strategy improvement arises from the general increase in the number of models to satisfy a wider range of customer markets which, in turn, is becoming more and more fragmented due to more demand for customization [7]. So the flexible product platform applying the attribute parameters to represents the modules and then the product variables can be propagated by changing the parameter values, while the modules are common with standard interfaces. The parameters are the characteristic of modules and the values of parameter satisfy different requirement of market niches.

The process of flexible platform design starts with market and customer needs analysis, identification of attribute character, judgement of platform parameter, modularization of product family, relation the modules and platform parameters, the last is configuration of modules to satisfy different customer needs. The platform elements are mapped from established design variables, and critical elements are identified through the change propagation analysis. The roadmap of the flexible product platform design is listed in Fig 1.

There are three keys to the flexible product platform design according to Fig.1. First is the product platform parameter which represents the common requirements of customer and the property of how product platform can satisfy all customer of the whole market niche. It is synthesized from all customer needs and transformed into the feature parameter. Second is the function modules of product which demand the independent relations between them. So it requires decomposing the overall function into independent levels of functional hierarchies and then the physical structure is integrated into physical to implement the functional modules, so that the different modules have no interaction and can be combined into variable products. Third is the relationship between modules and product platform parameters. After the modularity, these modules can be classified into flexible element that interrelate the main product 


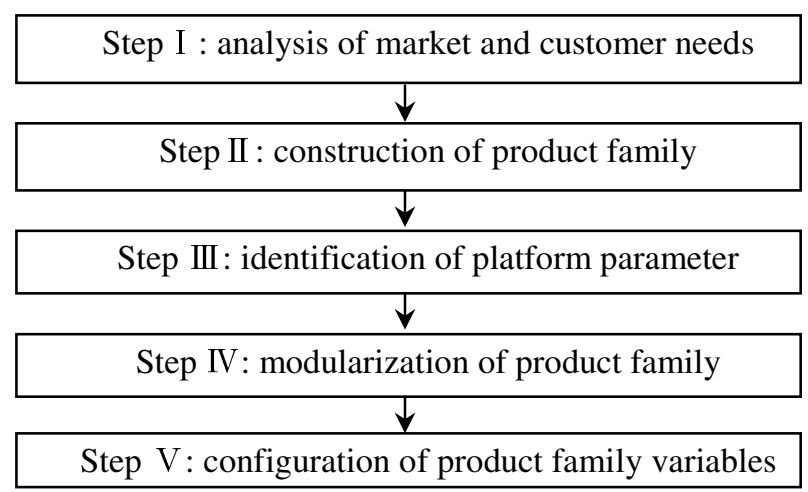

Fig. 1. The roadmap of flexible product platform

character and individual element that is changed according to the personal demands. The modules according to each main product character can be integrated into one flexible element and these flexible elements should be independent to each other for the changing of flexible element would not impact another.

\subsection{Step I - Analysis of Market and Customer Needs}

Customer need is the power of product development, so the customer need must be analysis detailed form the gathered customer information. Customer information is get by discussion, investigate, and observing the customer's application of product. Then these direct subjective demands is analyzed and induced to the real and inherent requirement of customer.

All the requirement of customer should be generalized into product attribute parameter so that the designer can easily understand the customer needs. Then a conjunction matrix of customer needs and attribute parameters is built, as shown in Fig.2. Each matrix element is represents the relation weight of corresponding customer need and attribute parameter. The meanings of matrix element values are listed in table 1.

\begin{tabular}{|c|l|l|l|}
\hline & Attribute parameter 1 & $\cdots$ & Attribute parameter $\mathrm{m}$ \\
\hline Customer need 1 & & & \\
\hline$\ldots$ & & & \\
\hline Customer need $\mathrm{n}$ & & & \\
\hline
\end{tabular}

Fig. 2. Conjunction matrix of customer needs and attribute parameters

Table 1. Meanings of element values in conjunction matrix

\begin{tabular}{|c|c|c|c|c|}
\hline Value & 9 & 6 & 3 & 0 \\
\hline Meanings & high & middling & low & Indifferent \\
\hline
\end{tabular}




\subsection{Step II - Construction of Product Family}

The market should be segmented into little cells according to the different customer requirements and the product family variables assembled by product platforms satisfy those requirements. The market segmentation selects the price and the product parameter values as the criterion. The price means the profit of product, and the product attribute parameters' values characterize individual customer requirements. There are stricter requirements of customer which will result the price of product is higher. In the next step the product family should be differentiate from all product variables with dynamic balance of price and parameter values. Then, firms can strategically position their product families in key market segments. So it demands on clearly and accurately defining the initial market segments.

The product family is relative to some market niches. The product platform is the core of how the product family implements the requirement of customer. But enterprise must consider the strategy how to make the most of the product platform to meet more market niches and reduce the redesign and complexity of product family. The four practiced platform strategies for the product family implementation are No Leveraging, Vertical Leveraging, Horizontal Leveraging, and the Beachhead Strategy, as shown in fig.3.

No Leveraging: The platform is designed exclusively for a single market segment. There is no other market segment that shares this particular platform. This strategy is usually implemented for a high performance product with relatively high development cost limits and performance tolerance range [7].

Vertical Leveraging: The platform is shared among low-end, mid-range and highend market segments within the same brand. It is "vertical" in a sense that a single platform is implemented from a low to high end of the market segment [7].

Horizontal Leveraging: The platform is shared across different brands but within the same class of market segment [7].

Beachhead Approach: This is the most ambitious platform strategy. A single platform is implemented across different brands and market segments [7].

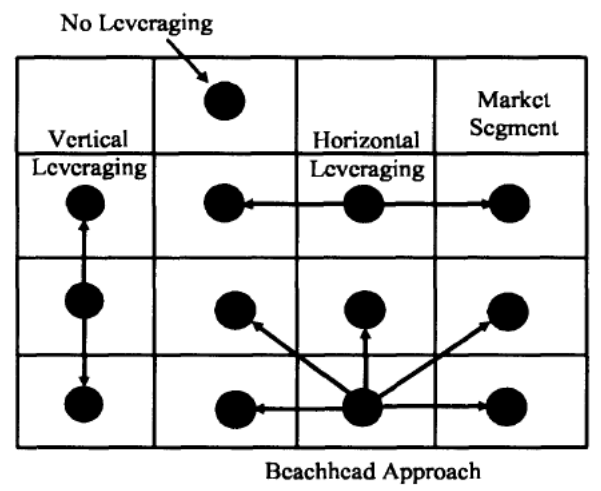

Fig. 3. Product Platform Deployment Strategies [7] 


\subsection{Step III - Identification of Platform Parameter}

The essence of flexible product platform is product attribute parameter represent the character of product platform and the different parameter values satisfy every market segments' requirements. So the parameter associated with product platform is defined as platform parameter, and it is the key to flexible product platform design. On one hand the platform parameters is common to all product variables of the market segments, on the other hand it have different values to realize the different requirement.

Parameter and customer needs. The product attribute parameters are generalized from the customer needs, and the customer needs are divided into general and personal customer needs in term of commonality and diversification. General customer needs are the basic requirement about product and the prime design intent. Personal customer needs are the special demands of customer about product. The product must content the basic and general requirement first and then satisfy the individual demands.

So after selection of product platform deployment strategy, the parameter values of all market niches can be identified. The relation between parameters and customer needs are established into a conjunction matrix by judging which parameter value would be affect when customer needs change. Then the parameter related to the general customer needs is taken for platform parameter.

\subsection{Step IV - Modularization of Product Family}

The flexible product platform is applied to solve the contradiction of modularity and commonality. It is same with high degree of modularity. The modules are clustered after the decomposition of functional and physical structure. First, the functional and physical structures are decomposed to divide the system into detailed sub-function and functional hierarchy. Then modules are confirmed according to the transfer and exchange of material, information and energy between sub-functions, as well as the structure interactions.

Modular structures require the independency of the functions [5]. But in the case of high degree of modularity, the customization focus on the structure modules and it require different values of the size, dimension, and other physical attributes. So the flexible product platform must keep the independence between the platform parameter and the physical structure modules. In this paper, the product family modularity is constructed according to the relation between physical structures and attribute parameters.

The product family is also collected from existing products. As to the high degree modularity product, the subassembly and parts are also considered as modules. To improve the flexibility of these modules, the product family should re-modularity by analysis the interaction of subassembly and attrib parameters. First a incidence matrix of subassembly and attrib parameters is built, and then a cluster identification algorithm [8] is introduced to build parameter-independent modules. Last the standard interfaces of these modules are constructed to implement the different platform parameter values modules combination.

The first row of incidence matrix is the product subassembly and first column of matrix is the attribute parameter. If the parameter $\mathrm{i}$ changing, the subassembly $\mathrm{j}$ will 
change all, then set matrix element Aij " 1 " which denote the interaction between parameters and subassemblies. The cluster identification algorithm is list as follow:

Step 1: Select any row i of incidence matrix and draw a horizontal line hi through it.

Step 2: For each entry of " 1 " crossed by the horizontal line $h_{i}$ draw a vertical line $v_{j}$.

Step 3: For each entry of " 1 "crossed by line $v_{j}$ draw a horizontal line.

Step 4: The preceding steps are repeated until no more crossed-once entries are left.

Step 5: The above procedure is repeated for the remaining matrix entries until all entries are grouped.

\subsection{Step V - Configuration of Product Family Variables}

The goal of flexible product platform is to improve the modules' flexibility and utility of quickly configuration of product variables with less redesign. The customization of product family with high degree modularity is mostly different attribute parameter values. The customer needs have already been translated into product attribute parameters correctly during step 1 . When the order is confirmed, the designer can quickly make sure all attribute parameters' value.So the configuration of product variables is the process of select the platform parameters' values according to the general customer needs, and then the platform architecture is identified. The individual modules will be added into product platform according the personal customer needs.

There may be also interactions between two attribute parameters which mean that the select sequence must be considered during the configuration. The sequence of configuration can be attained by the transforming the conjunction matrix of the customer needs and attributed parameters constructed in the step 1. The row with one nonzero element denotes that the parameter is only associated with one customer need and its values can be selected firstly. Other parameter's values can be selected with the consideration of influence about those all ready selected parameter values. So combine the product platform and parameter values selected consequence, the configuration process can be built to implement the prompt design of product family.

\section{Flexible Product Platform Design of CNC Grinder}

Tianjin NO2. Machining Ltd. is a enterprise of CNC grinder producer. CNC grinder is a typical customized product. Customer will select the $\mathrm{CNC}$ grinder according to parts which they are going to produce. As the same time, $\mathrm{CNC}$ grinder is also a high degree modularized product. So building the flexible product platform of $\mathrm{CNC}$ grinder is a helpful method to improve the efficiency and accuracy of redesign and prompt configuration for the customization of CNC grinder.

1. Analysis of market and customer needs

The CNC grinder is a machining tool of bearing. So the machining dimension and tolerance of parts is most important common factors for the CNC grinder customization. These two factors determine the size and precision which are the basic features of $\mathrm{CNC}$ grinder. Besides these main factors, there are also many accessional 


\begin{tabular}{|c|c|c|c|c|c|c|c|c|c|c|c|c|c|}
\hline & 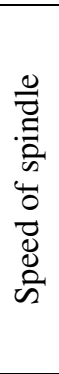 & 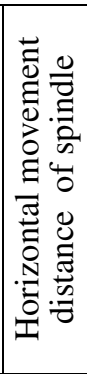 & 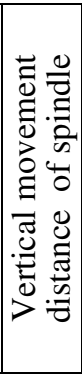 & 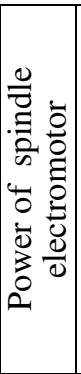 & 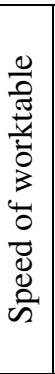 & 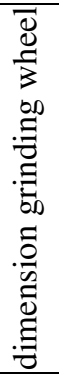 & 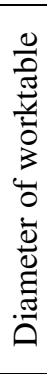 & 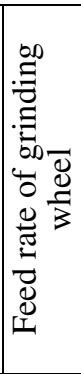 & 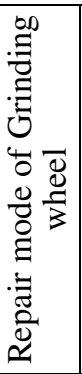 & 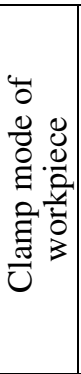 & 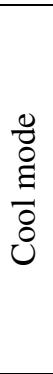 & $\begin{array}{l}\frac{\mathscr{Z}}{\delta} \\
\Xi \\
\bar{\Xi} \\
\stackrel{0}{0} \\
\stackrel{0}{0}\end{array}$ & 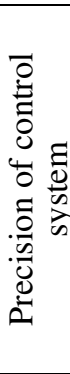 \\
\hline $\begin{array}{c}\text { Machining } \\
\text { Scope }\end{array}$ & 0 & 6 & 9 & 3 & 0 & 3 & 9 & 0 & 0 & 3 & 0 & 0 & 3 \\
\hline $\begin{array}{c}\text { Operation } \\
\text { Convenience }\end{array}$ & 0 & 0 & 0 & 0 & 0 & 3 & 6 & 0 & 0 & 3 & 3 & 0 & 3 \\
\hline $\begin{array}{c}\text { Machining } \\
\text { Quality }\end{array}$ & 6 & 0 & 0 & 0 & 3 & 3 & 0 & 6 & 0 & 0 & 3 & 3 & 3 \\
\hline $\begin{array}{l}\text { Moderate } \\
\text { Price }\end{array}$ & 0 & 6 & 6 & 3 & 0 & 0 & 3 & 0 & 0 & 3 & 3 & 3 & 3 \\
\hline $\begin{array}{c}\text { High } \\
\text { efficiency }\end{array}$ & 9 & 3 & 3 & 6 & 3 & 3 & 0 & 9 & 3 & 3 & 0 & 0 & 0 \\
\hline $\begin{array}{c}\text { Safety \& } \\
\text { Credibility }\end{array}$ & 0 & 0 & 0 & 0 & 3 & 0 & 0 & 0 & 3 & 3 & 0 & 3 & 0 \\
\hline $\begin{array}{c}\text { Long } \\
\text { Employ Life }\end{array}$ & 0 & 0 & 0 & 0 & 0 & 0 & 0 & 0 & 0 & 0 & 0 & 0 & 3 \\
\hline $\begin{array}{c}\text { Maintain } \\
\text { Convenience }\end{array}$ & 0 & 0 & 0 & 0 & 0 & 0 & 6 & 0 & 3 & 3 & 3 & 3 & 0 \\
\hline
\end{tabular}

Fig. 4. The relation matrix of CNC grinder's customer and attribute parameters

requirements such as the control system, detection on line, and the clamp etc. Every CNC grinder must redesign according to the individual customer requirement because that every part's dimension and tolerance, as well as the different customer desire. The conjunction matrix of CNC grinder is listed in fig.4.

\section{Construction of product family}

According to the Table 1 and CNC grinders' market segment is carried out according to the price and machining precision. The market niches include ultra precision, high precision and ordinary precision niches. Different precision requires different parts and assembly with different cost. The flexible product platform is to applied for more and more market niches, so the product family deployment strategies is select as the beachhead approach.

Tianjin NO2. Machining tool producing Ltd. has already product high precision CNC grinder with the machining ability of 1.6 meters. The flexible product platform is based on this CNC grinder, and by building the parameter independent modules to 
extent the product satisfying much more market niches. For the horizontal extension, the product platform can satisfy different machining ability. For the vertical extension, the product platform can satisfy different machining precision.

\section{Identification of platform parameter}

The machining scope and quality of CNC grinder are general customer needs according to the customer needs analysis. So the platform parameter is the attribute parameters which have high interaction with these two customer needs. Then analyzing the conjunction matrix (Fig.4) according to the element values which is 9 or 6 means high interaction. The Horizontal movement distance (denoted as $x$ ) and vertical movement distance (denoted as $z$ ) of spindle and diameter (denoted as $R$ ) of worktable is highly related with machining scope. The speed of spindle and feed rate of grinding wheel is highly related with machining quality. The machining quality is determined by the precision of spindle (denoted as $S P$ ). The platform parameters are generalized as $x, z$, $R, S P$.

\section{Modularization of product family}

The CNC grinder is a high degree modularity product. In this step, the modularity is to build parameter independent modules. The first of modularity is identification of $\mathrm{CNC}$ grinder assemblies and parts and building the relating effect between the parameter and assemblies or parts. Then the cluster identification algorithm is applied to combine the assemblies and parts into blocks and keep the independence with parameter. So when one platform parameter changing the related modules will change and without effect to other modules. The result of CNC grinder modularity is shown in Fig.5 and the independent relation is list in Table 2.

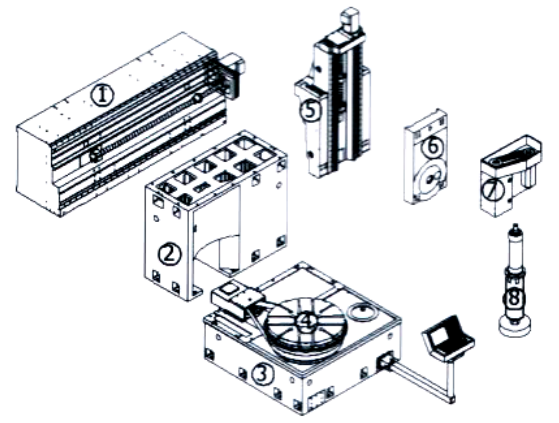

$\mathrm{M}_{1}:$ Transom
$\mathrm{M}_{2}:$ Column
$\mathrm{M}_{3}:$ Bed
$\mathrm{M}_{4}:$ Worktable
$\mathrm{M}_{5}:$ Carriage
$\mathrm{M}_{6}:$ Slide
$\mathrm{M}_{7}:$ Grinding
Frame
$\mathrm{M}_{8}:$ Wheel Spindle

Fig. 5. Modularity of CNC grinder

Table 2. The relation of modules and platform parameters

\begin{tabular}{|r|r|r|r|r|r|r|r|r|}
\hline & $\mathrm{M}_{1}$ & $\mathrm{M}_{2}$ & $\mathrm{M}_{3}$ & $\mathrm{M}_{4}$ & $\mathrm{M}_{5}$ & $\mathrm{M}_{6}$ & $\mathrm{M}_{7}$ & $\mathrm{M}_{8}$ \\
\hline$x$ & $\times$ & & & & & & & \\
\hline$z$ & & $\times$ & & & $\times$ & & & \\
\hline$R$ & & & $\times$ & $\times$ & & & & \\
\hline$S P$ & & & & & & $\times$ & $\times$ & $\times$ \\
\hline
\end{tabular}


There are also personal modularity such as grinding wheel repair device, chuck, cool system, and defence, check online system etc. They are related with individual parameters.

\section{Configuration of product family variables}

The CNC grinder's flexible element can be make off four parts which is the modules related with those four platform parameters. When configuration designer can select different valve of these four platform parameters and assemble the physical modules into a product platform. Then the individual element is also appended so the product varieties satisfying different customer in a market niche is developed.

\section{Conclusion}

The flexible product platform solves the conflict of modularity's variety and efficiency. The platform parameters denote the common properties of product platform and different values of those parameters realize the flexible of product platform. Then the parameter-independent modules can be combined into a physical product platform and extend to satisfy much more market segments. The flexible product platform of CNC grinder improves the reutilization and guides the designer promptly to develop the individual CNC grinder for personal customer needs.

\section{Acknowledgments}

Authors are grateful to the Natural Science Foundation of Hebei Province (No. E2008000086), Natural Science Foundation of Tianjin (No.07JCZDJC08900), the Key Project of the Ministry of Science and Technology of the People's Republic of China (2008IM030100), Scientific Research Projects of Education Office of Hebei Province (2008428) and Scientific Research Projects of Education Office of Hebei Province (07217129) for funding this work.

\section{References}

1. Chen, Y.J.: An integrated Process Planning and Production Scheduling Framework for Mass Customizitaion, Ph.D. dissertation, The Hong Kong University of Science and Technology (2003)

2. Meyer, M.H., Lehnerd, A.P.: The Power of Product Platforms: Building Value and Cost Leadership. Free Press, New York (1997)

3. Timothy, W.S., Jonathan, R.A.M.: Product platform design: method and application. Res. Eng. Design 13, 2-22 (2001)

4. Kamrani Ali, K.: Product Design for Modularity. Ph.D. dissertation, Sa'ed Salhieh Kluwer Academic Publishers (2000)

5. Jiang, P., Zhao, X.P., Yang, B.J., et al.: The Product Family Design Based on Axiomatic Design. In: IEEM 2007 (2007)

6. Simpson, T.W., Siddique: Product Platform and Product Family Design, Methods and Applications. Springer Science, New York (2006)

7. Suh, E.S.: Flexible Product Platforms. Ph.D. dissertation, Massachusetts Institute of Technology (2005)

8. Kusiak, A.: Intelligent Design and Manufacturing. John Wiley\& Sons, New York (1992) 